\title{
Erratum: preventing the development of depression at work: a systematic review and meta-analysis of universal interventions in the workplace
}

\author{
Leona Tan ${ }^{1 *}$, Min-Jung Wang ${ }^{1}$, Matthew Modini ${ }^{1}$, Sadhbh Joyce ${ }^{1}$, Arnstein Mykletun ${ }^{2}$, Helen Christensen ${ }^{3}$ \\ and Samuel B Harvey ${ }^{1,3,4}$
}

\section{Erratum}

\section{Authors' correction note:}

Upon reviewing our recently published review [1], we discovered that two of the nine studies we identified in our meta-analysis were in fact using results from the same dataset. We would not normally include the same data twice in a meta-analysis, so since discovering this we have re-run the analysis removing one of the studies [2]. This resulted in a very slight change in the pooled effect size for workplace universal interventions on depression measures (was originally 0.16 , now $0.17,95 \%$ CI: $0.07,0.27)$ and the subgroup analysis of cognitive behavioural therapy-based universal prevention interventions on depression measures (remains unchanged at 0.12 , but with a slight alteration in the confidence intervals, 95\% CI: $-0.01,0.24)$. These are very minor changes in effect sizes which do not change our overall conclusions regarding the effectiveness of workplace universal interventions.

\section{Corrected text:}

(Page 1: Abstract, final sentence of Results)

Please replace:

A separate analysis using only CBT-based interventions yielded a significant SMD of 0.12 (95\% CI: 0.02, $0.22, P=0.01$ ).

With the amended text:

A separate analysis using only CBT-based interventions yielded a SMD of 0.12 ( $95 \% \mathrm{CI}$ : $-0.01,0.24, \mathrm{P}=0.07$ ).

\footnotetext{
* Correspondence: leona.tan@unsw.edu.au

${ }^{1}$ University of New South Wales, School of Psychiatry, Black Dog Institute, Prince of Wales Hospital, Hospital Road, Randwick, NSW 2031, Australia Full list of author information is available at the end of the article
}

(Page 5: Results. Overview of search results and included studies)

Please add the following text at the end of the second paragraph:

However, upon closer inspection two studies [2,3] were found to have used the same dataset which resulted in one

[2] of these being excluded from the meta-analysis.

(Page 6: Effects of workplace intervention program compared to control conditions, first paragraph)

Please replace:

Figure 2 presents the SMDs at post-test and the pooled mean effect size using the random effects model (REM), for the nine studies included in the meta-analysis. The overall mean difference between the intervention and control groups was 0.16 (95\% CI: 0.07, 0.24, P = 0.0002), with effect sizes varying from small negative effects $(d=-0.01)$ to moderate positive effects $(\mathrm{d}=0.61)$. No heterogeneity was detected $(\mathrm{Q}=6.56 ; \mathrm{I} 2=0 \% ; \mathrm{P}=0.68)$. As noted above, more than half of the included studies $(n=5)$ examined the impact of interventions based on CBT. A separate meta-analysis including only CBT-based intervention studies was conducted, the results of which are presented in Figure 3. The overall mean difference between CBTbased interventions and the control groups was $0.12(95 \%$ CI: $0.02,0.22, \mathrm{P}=0.01$ ), indicating a positive effect for CBT-based interventions. There was no evidence of heterogeneity in this analysis $(\mathrm{Q}=5 ; \mathrm{I} 2=0 \% ; \mathrm{P}=0.93)$.

With the amended text:

Figure 2 presents the SMDs at post-test and the pooled mean effect size using the random effects model (REM), for the eight studies included in the metaanalysis. The overall mean difference between the intervention and control groups was 0.17 (95\% CI: 0.07, 0.27, $\mathrm{P}=0.0009)$, with effect sizes varying from small negative effects $(d=-0.01)$ to moderate positive effects $(d=0.61)$. 
No heterogeneity was detected $(\mathrm{Q}=6.44 ; \mathrm{I} 2=0 \% ; \mathrm{P}=0.60)$. As noted above, more than half of the included studies $(n=5)$ examined the impact of interventions based on CBT. A separate meta-analysis including only CBT-based intervention studies was conducted, the results of which are presented in Figure 3. The overall mean difference between CBT-based interventions and the control groups was 0.12 (95\% CI: $-0.01,0.24, \mathrm{P}=0.07)$, indicating a small effect, of borderline statistical significance, for CBT-based interventions. There was no evidence of heterogeneity in this analysis $(\mathrm{Q}=1.28 ; \mathrm{I} 2=0 \% ; \mathrm{P}=0.86)$.

(Page 9: Discussion, first paragraph)

Please delete:

When analyzed separately universally delivered CBTbased interventions significantly reduced levels of depressive symptoms among workers.

(Page 10: Conclusions)

Please replace:

Specifically, workplace CBT-based interventions are effective at universal symptom reduction for depression.

With amended text:

There is emerging evidence that workplace CBT-based interventions are likely to be effective at universal symptom reduction for depression.

\section{Author details}

'University of New South Wales, School of Psychiatry, Black Dog Institute, Prince of Wales Hospital, Hospital Road, Randwick, NSW 2031, Australia. ${ }^{2}$ Norwegian Institute of Public Health, Bergen, Norway. ${ }^{3}$ Black Dog Institute, Prince of Wales Hospital, Hospital Road, Randwick, NSW 2031, Australia.

${ }^{4}$ St George Hospital, Gray Street, Kogarah, NSW 2217, Australia.

Received: 10 October 2014 Accepted: 10 October 2014

Published online: 13 November 2014

\section{References}

1. Tan L, Wang MJ, Modini M, Joyce S, Mykletun A, Christensen H, Harvey SB: Preventing the development of depression at work: a systematic review and meta-analysis of universal interventions in the workplace. BMC Med 2014, 12:74.

2. Vuori J, Toppinen-Tanner S, Mutanen P: Effects of resource-building group intervention on career management and mental health in work organizations: randomized controlled field trial. J Appl Psychol 2012, 97:273-286.

3. Ahola K, Vuori J, Toppinen-Tanner S, Mutanen P, Honkonen T: Resourceenhancing group intervention against depression at workplace: Who benefits? A randomised controlled study with a 7-month follow-up. Occup Environ Med 2012, 69:870-876.

\section{Submit your next manuscript to BioMed Central and take full advantage of:}

- Convenient online submission

- Thorough peer review

- No space constraints or color figure charges

- Immediate publication on acceptance

- Inclusion in PubMed, CAS, Scopus and Google Scholar

- Research which is freely available for redistribution 